\title{
Using Facebook To Find Missing Persons: A Crowd-Sourcing Perspective
}

\author{
MJ Hattingh*, MC Matthee \\ Department of Informatics, University of Pretoria, South Africa \\ \{Marie.Hattingh, Machdel.Matthee\} dup.ac.za
}

\begin{abstract}
This paper explores the ways in which Facebook is used in the quest for finding missing persons in South Africa. Graphs are used to indicate differentiated roles of the Facebook communities: some communities act mainly as originators of the messages whereas others act more as distributors or end points of the messages. Crowd-sourcing is used as a conceptual tool to further our understanding of the way messages are shared among different Facebook communities. The four pillars of crowdsourcing as proposed by Hosseini et al, are used to analyse the network of communities as a crowd-source system. It is argued that Facebook can be effective as crowdsourcing system despite the fact that there is no guarantee that missing persons reported there will be found, since it most likely provides much needed emotional support to friends and relatives of the missing person.
\end{abstract}

Keywords: Crowdsourcing, social media, Facebook, missing people, emotional support

\section{Introduction}

"A child goes missing in South Africa every five hours" [1]. This alarming fact is not just restricted to children and also not to just South Africa, but is a world-wide problem. Scoop [2] reported in 2013 that 4,432,880 people have disappeared in the past 20 years worldwide. The ubiquity of technology gives people/ organisations additional tools to assist in the search for missing people. Centralized databases (registers) can be constructed and information can be shared with ease [3]. Previously, this type of information was usually controlled and distributed through formalized organisations such as the law enforcement services. However, with the rise in the uptake of social media, ordinary citizens can now contribute to the search of missing persons through Web 2.0 technologies. In South Africa, the social media platform adoption has changed significantly. The 2014 World Wide Worx and Fuseware report [4] has indicated that Facebook is the biggest social media adfa, p. 1, 2011.

CC Springer-Verlag Berlin Heidelberg 2011 
platform in South Africa. The report indicated that there are 9.4 million active Facebook users in South Africa in 2014 compared to 6.8 million users in 2013. People use these social media platforms to create social networks. However, these social networks can now be used as a problem solving tool, where a problem is being "outsourced" to the "crowd", this is known as crowdsourcing [5]. Taking the problem solving abilities of networks of people in consideration this study is attempting to answer the following question: How do people use social media platforms, such as Facebook, to aid the search of missing persons? This problem is approached from a crowdsourcing perspective. Crowds usually originates as an undefined network of people that contribute to a particular task [5]. We answer the research question by firstly mapping the interaction of Facebook groups/pages dedicated to finding missing persons in South Africa and secondly using crowdsourcing as analytical lens, to understand how Facebook communities interact in the quest for finding missing persons.

The paper will first provide in section two some background on missing persons which is followed by a brief discussion on the use of social media as a crowdsourcing tool in section three. After this, in section four, data is presented on a snapshot taken from a particular network of Facebook groups. The snapshot is analysed in section 5 using the four pillars of crowdsourcing. This is followed by the discussion and conclusion of the findings in sections six and seven respectively.

\section{$2 \quad$ Missing Persons And Social Media}

According to the "Missing persons: A handbook for parliamentarians" [3], a missing person is defined as an "individuals of whom their families have no news and/or who, on the basis of reliable information, have been reported missing..." With the advent of technology, one would intuitively assume that the search for missing persons will be made easier. However, that is not always the case. Missing Children SA representative says that "Every year we see our success rate decrease. It's not necessarily because we're finding less people, it's just because more people are hearing about the service that "Missing Children SA" provides" [6].

Missing persons is a societal problem that extends beyond finding the missing person. Support to the families of the missing person is also important. 
According to Wayland [7] the police and non-police search agencies are the primary support mechanisms for the family members as the "the initial focus is on the physical location and return of the missing person and the emotional needs of the family are often set aside while these practical issues are dealt with". Social media can extend support to families of missing person by rendering emotional support. Johnson et al [8] state that when people are embedded in a caring network, such as a Facebook community dedicated to the search of finding missing people, they are able to obtain social resources, such as instrumental and emotional support, to cope with daily stress or uncertainty. This is extended by Wang and Nayir [9] that stated informal and formal social networks, such as Facebook communities, offer access to resources, to social and emotional support and to practical help for coping with personal, economic and social problems.

\section{Crowdsourcing}

Hosseini et al [10] identify four parts (or pillars) of crowdsourcing that describes the entire operation: (1) The crowd: describing the diversity of the people who take part in the crowdsourcing activity, whether they are known to the crowdsource or each other, whether they are enough to fulfil the task without being overloaded, how they were involved to take part and whether they are willing and able to take part, (2) The Crowdsourcer: the person or organisation that needs the help of the crowd to solve a problem The crowdsourcer might rely on intrinsic or extrinsic motivation, extending the call to participate to the general public in an ethical way. (3) The Crowd-sourced task: This recognises the traditional way the task would have been completed if crowdsourcing did not occur as well as the complexity, solvability, ability to automate, the role of the crowd and the type of contribution made by the crowd. (4) The Crowdsourcing Platform: This refers to the interaction between the crowd and the platform such as social media, the interaction between the crowdsourcer and the platform, the functionalities provided by the platform.

There are a number of existing crowdsourcing tools that use social media to reach the crowd. One such an example is Ushahidi, an open source crises map platform, which was used for disaster relief during the earthquake in Haiti [11]. Rahwan et al [12] explain how they used social media to crowdsource rapid information gathering in order to find five wanted per- 
sons during a manhunt challenge. Their biggest challenge was to mobilize participants to share messages. Gao [11:12] found that during disaster relief, social media as crowdsourcing mechanism provides "aggregate situational awareness, important and new communications pathways, and some opportunities for assistance on an individual level."

\section{Method}

On the 7th of March 2016, the lead researcher typed in "Missing people" in Facebook search engine. The first public South African Facebook group dedicated to locating missing people, was identified as "Missing People in Centurion" (MPC). The lead researcher then considered every post of the MPC Facebook group between 7 March 2016 and 1 October 2015, giving her approximately 6 months' posts to analyse. Table 1 below illustrates the data captured during the first search iteration.

Table 1. Data captured from first Facebook community

\begin{tabular}{|c|c|c|c|c|c|c|c|c|c|c|c|c|c|c|c|c|c|c|c|c|}
\hline \multirow{2}{*}{\begin{tabular}{|l|} 
A \\
MPC \\
\end{tabular}} & \multirow{3}{*}{\begin{tabular}{|l|}
\multicolumn{1}{|c}{ B } \\
Missing people in Centurion \\
Groups Posted
\end{tabular}} & \multicolumn{19}{|c|}{ c } \\
\hline & & \multicolumn{3}{|c|}{689 members } & & & & & & & & & & & & & & & & \\
\hline & & & & & & & & & & & & & & & & & & & & \\
\hline PL & Minors Missing - The pink ladies org for missing children & $\mathrm{FC}$ & MC & $\mathrm{FA}$ & MC & FA & MC & $\mathrm{FA}$ & $\mathrm{FCD}$ & FC & FA & $\mathrm{FC}$ & FA & FC & MC & MC & MA & MC & $\mathrm{FC}$ & MA \\
\hline Hi5kids & Hi5 Kids recovery & MC & FC & FC & & & & & & & & & & & & & & & & \\
\hline MCSA & Missing Chidren SA & MC & FA & FA & MC & FC & FA & FC & MC & FC & $\mathrm{FC}$ & MA & MA & MA & MA & MA & FA & & & \\
\hline NP-BVEN & NewsPaper - Bedørdviewedenvalenews & MC & & & & & & & & & & & & & & & & & & \\
\hline SAPS & South Afican Police Services & FCD & & & & & & & & & & & & & & & & & & \\
\hline NP-RK & NewsPaper - Rekord & MA & MA & MA & MA & & & & & & & & & & & & & & & \\
\hline NP-KM & NewsPaper-Kormorant & MC & & & & & & & & & & & & & & & & & & \\
\hline NP-MM & NewsPaper - Maroelamedia & MC & & & & & & & & & & & & & & & & & & \\
\hline PLC & People who live in centurion & FA & FA & FA & & & & & & & & & & & & & & & & \\
\hline BCPF & Vulnerable Citzens Support Initafive:Benoni CPF & MC & MC & & & & & & & & & & & & & & & & & \\
\hline Pvt & Privale Posts & FA & MA & FA & MA & FA & FA & FA & FC & MA & MA & MC & MA & & & & & & & \\
\hline KCF & Krugersdorp Community forum & MA & & & & & & & & & & & & & & & & & & \\
\hline GPFW & GPF Wigehof & MC & & & & & & & & & & & & & & & & & & \\
\hline NP-MS & NewsPaper - Mobserver & MC & & & & & & & & & & & & & & & & & & \\
\hline $\operatorname{CCC}$ & Centurion concerned citizens & FA & FA & MC & & & & & & & & & & & & & & & & \\
\hline
\end{tabular}

For every Facebook community with its accompanying posts, she captured the following information in an MS Excel spreadsheet, (as illustrated by Table 1 above, which represents the data captured for the first Facebook community reviewed): (1) The group the post originated from (column B). An acronym was assigned to each group in column A. (2) Each post that was distributed by each of the groups (column C). Distinction was made between posts depending on whether it was an adult or child that was missing or found or deceased. The following codes were used: a missing child (MC), a missing adult (MA), child found (FC), found adult (FA). In a few instances the post reported that a child was found deceased (FCD) or an adult was found de- 
ceased (FAD). All duplicate posts from the same group were ignored. Finally, the lead researcher then repeated the above steps for the six dedicated "missing people" or community support Facebook groups that were listed in the first group (Table 1, column B), excluding newspapers and private pages, until saturation was reached (no new communities emerged).

\section{Data Analysis}

Table 2 below illustrates the data that was obtained from the Facebook review. Seven Facebook communities dedicated to finding missing people or community support communities were found, linked directly or indirectly to the first Facebook group. In total, 392 posts were reviewed within the given 6 month timeframe. These Facebook communities were connected to a total of 38 other communities ( 45 communities in total). Table 2 above summarises all the communities reviewed where the size of the community is indicated by both the number of members/likes of the community, and the types and number of posts distributed by each of these communities.

Table 2. Summary of Facebook Communities identified

\begin{tabular}{|c|c|c|c|c|c|c|c|c|}
\hline Facebook Group/Page name & $\begin{array}{l}\text { Members } \\
\text { /likes }\end{array}$ & $\begin{array}{l}\text { Connec- } \\
\text { tions }\end{array}$ & FA & FC & MA & MC & FCD & FAD \\
\hline $\begin{array}{l}\text { 1. Missing people in Centurion } \\
\text { (MPC) }\end{array}$ & $\begin{array}{l}689 \\
\text { members }\end{array}$ & 15 & 18 & 11 & 17 & 19 & 2 & 0 \\
\hline $\begin{array}{l}\text { 2. Minors missing - the Pink } \\
\text { Ladies org for missing children } \\
\text { (PL) }\end{array}$ & $\begin{array}{l}28030 \\
\text { likes }\end{array}$ & 0 & 5 & 7 & 95 & 31 & 0 & 0 \\
\hline 3. Hi5 Kids Recovery (Hi5K) & 9193 likes & 3 & 2 & 7 & 3 & 1 & 1 & 0 \\
\hline 4. Missing Children SA (MCSA) & $\begin{array}{l}62621 \\
\text { likes }\end{array}$ & 0 & 19 & 28 & 32 & 17 & 0 & 3 \\
\hline $\begin{array}{l}\text { 5. Vulnerable Citizens Support } \\
\text { Initiative:Benoni CPF: Gauteng } \\
\text { Community Alerts (BCPF) }\end{array}$ & $\begin{array}{l}7468 \\
\text { members }\end{array}$ & 11 & 1 & 11 & 11 & 8 & $2^{*}$ & 3 \\
\hline $\begin{array}{l}\text { 6. People who live in Centurion } \\
\text { (PLC) }\end{array}$ & $\begin{array}{l}31556 \\
\text { members }\end{array}$ & 11 & 1 & 3 & 6 & 2 & $2^{*}$ & 0 \\
\hline $\begin{array}{l}\text { 7. Centurion Concerned Citi- } \\
\text { zens (CCC) }\end{array}$ & $\begin{array}{l}24256 \\
\text { likes }\end{array}$ & 5 & 13 & 7 & 3 & 0 & 1 & 0 \\
\hline
\end{tabular}

The connectivity between the different Facebook communities is illustrated by Figures 1 and 2 which represents the connections (and thereby the reach) of the Facebook crowd. In Figure 1 each Facebook community is represented by a node whereas each line represents a one-directional information flow between two Facebook communities. The arrow points to the community that shares the posts of the connected Facebook community. For example, 
the Pink Ladies is dedicated to finding missing persons and can therefore be seen as the originator of the posts. Indeed, Figure 1 shows that the Pink Ladies (PL) has the most references (shared posts) by other communities, followed by the Missing Children SA (MCSA) group who is also dedicated to finding missing persons. The third most-shared posts originate from private people (PVT) reporting missing people. This is indicated by the sizes of the nodes.

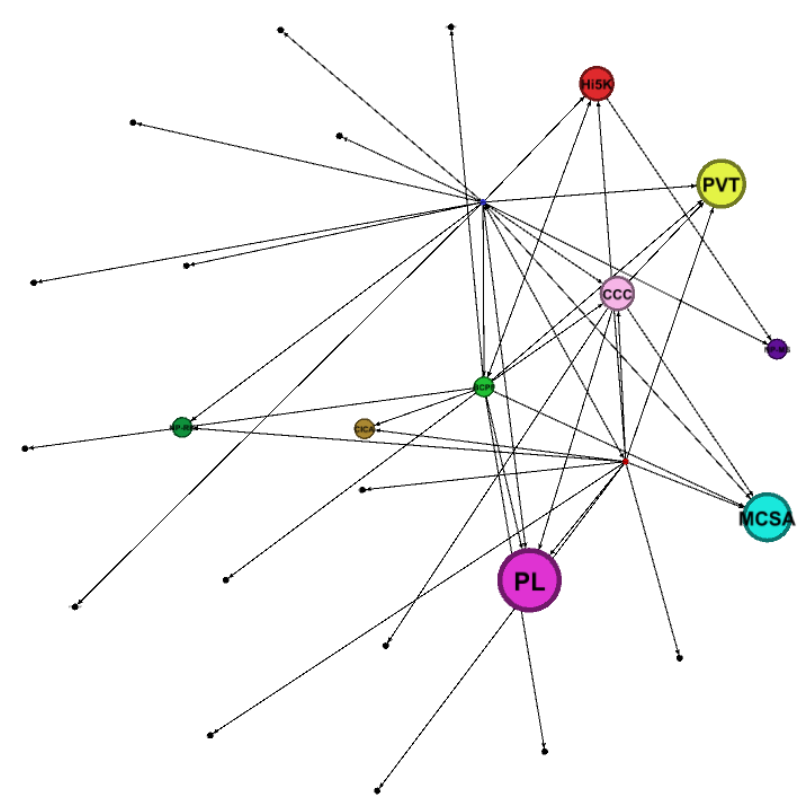

Fig. 1. Originators of posts

Figure 2 illustrates a different kind of information flow. The lines of the graph and size of the nodes now refers to the number of posts shared by that specific community of other communities. It further shows in Figure 2 that even though PL's posts were shared the most among different communities, PL did not share any posts associated with other communities (within the research period). Similarly, the posts of MCSA were widely shared, but MCSA did not share any other communities' posts on their page. Both these communities' nodes are therefore very small. However, the first Facebook group reviewed by the researchers, MPC, shares a lot of posts of other communities as indicated by the size of the node. The second and third biggest sharer of posts of other communities are PLC and BCPF. MPC is a community dedi- 
cated to finding missing people whereas the PLC and BCPF are community support groups.

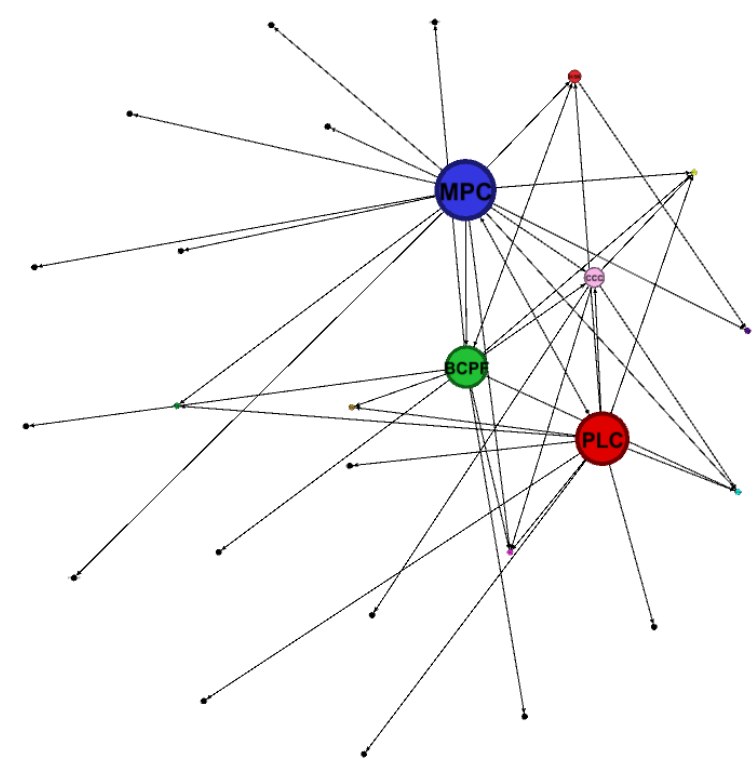

Fig. 2. Distributors of posts

The maps provided in Figures 1 and 2 show the 'enlarging of the search party' across diverse geographic areas and thousands of people. It also shows differentiated roles of the communities: some communities act mainly as originators of the messages whereas others act more as distributors or end points of the messages. The following sections will analyse the above Facebook communities according to the four pillars of crowdsourcing as defined by [10].

\subsection{Pillar One: The Crowd}

In this paper the crowd refers to the Facebook community members sharing the posts of various Facebook communities (illustrated in Figure 2). Their features are as follows: Diversity: The diversity needed in this crowd is from a geographical perspective. This was indeed reached since the initial group reviewed by the researchers is situated in Gauteng, South Africa, but posts as far as Kraaifontein in the Western Cape Province some $1000 \mathrm{~km}$ from Gauteng, were identified. Unknownness: Due to the nature of Facebook, the 
crowd will inevitably know about one another as anyone can have at least limited access to anyone's profile. However, the aim of this exercise is not anonymity but is in support of the crowdsourcer's task. In the majority of instances the missing person post/update was made by the specific Facebook community, as illustrated in Figure 1 above, only $10 \%$ of all the posts under consideration (26 of 393 posts) were private posts. Largeness: The largeness of the networked Facebook communities, is what makes the Facebook platform so successful in finding missing people. Table 2 above illustrates, that between the communities under consideration, there is a crowd of 163813 Facebook users that would be able to assist in the quest to find missing people. Undefined-ness: The vast amount of Facebook users is an illustration of the undefined-ness of the Facebook social network. All of the groups, bar the private posts, were public groups which allowed anyone access to their postings. Suitability: The Facebook communities referenced in this study all voluntarily participated in solving the "missing people" problem by posting the "missing people" information, or share the posted information. The number of communities referenced by particular communities is an illustration of their ability to collaborate with other communities and individuals. The Facebook communities' motivations are all intrinsic as no incentive, bar the possibility of locating the missing person is provided.

\subsection{Pillar Two: The Crowdsourcer}

In this paper the crowdsourcer refers to the Facebook communities and community members (in terms of private posts) who provide the posts of missing persons (illustrated in Figure 1). A missing person post usually includes personal details with a photo as well as contact details of the authorities and a contact number of the missing persons community representative. The features of the crowdsourcer in this context are as follows: Incentive provision: There was no need for the crowdsourcers (the different communities listed in Table 2 or the private posts) to provide any incentives for "the crowd" to participate in posting or sharing missing people information. Open Call: As all the groups were public groups, it was open for any member of the public to participate in the posting or sharing of missing people. Ethicality provision: At any stage can a member of "the crowd" choose not to participate, or even "opt-out" of the Facebook group by unfollowing the page or removing themselves from the group. Furthermore, the crowdsourcer is ethically bound to provide feedback to "the crowd". From Table 2 it is seen that 
updates were made where available. Privacy provision: Due to the nature of Facebook it is near impossible for "the crowd" not to be aware of one another. However, it is possible for the crowd to private message the crowdsourcer, which the crowdsource is not allowed to disclose to others.

\subsection{Pillar Three: The Crowdsourced Task}

In this paper the crowdsourced task refers to the activity of locating missing people. There features are as follows: Traditional operation: The missing people's communities work in conjunction with the authorities to locate the missing persons. In most cases, if the missing person's notice is released through a missing person's community (such as MCSA or PL) a police docket number is included (if available)). This allows for the traditional operations to continue parallel with the community's crowdsourcing initiative. Modularity: Although a number of posts can be posted daily regarding missing people, it is done one by one. Therefore, "the crowd" can choose the post which they would like to share. Complexity: Task of sharing a Facebook post is quite straightforward and the community was quick to assist if someone had trouble sharing a post. Solvability: Unfortunately, the act of sharing a post does not necessarily result in solving the missing person problem. However, a secondary activity of the ability to support the crowdsourcer emotionally (especially if it is a private post) can be seen as solving the emotional isolation problem. An example of this is a message posted on MPC (Missing Persons in Centurion): "Morning all, my brother has been missing for 2 weeks now. I ask that we all pray for his safe return where ever he might be, also if anyone knows or have seen him please contact me at this number" on which MPC replied: "Hi, why don't we all just re-share this and ask our contacts to share so the word spreads more and more". Automation Characteristics: The nature of Facebook allows for a measure of automation. Once a Facebook user "follows" a group he/she will automatically receive the post from the group (the crowdsourcer), however, the act of further sharing it is not automated. Furthermore, this is an inexpensive method of automation. User-driven: The particular problem that is attempted to be solved through "the crowd" is creating awareness and finding missing people. This is problem solving activity but also an example of an innovative way of using technology. Contribution Type: The Facebook communities allow for both an individual and collaborative contribution. Collectively the various communities are working together to find missing people. However, on an individual level, a communi- 
ty member renders support to the crowdsourcer (in the event of an individual/private post).

\subsection{Pillar Four: The Crowdsourcing Platform}

In this paper the crowdsourcing platform refers to Facebook. Its features are as follows: Crowd-related Interactions: Facebook as the chosen crowdsourcing platform in this instance provides clear mechanisms for enrolment and authentication (as far as user profiles are legitimate). In certain instances, especially when it's a private post, the community members were asked to share the missing person's details, however, in formal missing person's posts, the communities spontaneously shared posts without being "tasked" to do it. Crowdsourcer-related Interactions: The crowdsourcer in this study took two forms: dedicated missing people group administrators who generate and co-ordinate posts regarding missing people as illustrated in Figure 1 above and secondly, individuals sharing private posts (usually about someone close to them) being missing. In both these instances, Facebook has clear rules in place regarding privileges of users and administrators. Task-related Facilities: The communities provided no restriction on the sharing of posts regarding missing people. Furthermore, the crowdsourcers (not in the case of private posts) usually work closely with the authorities in order to ensure the authentication of the "task". Platform-related Facilities: The online platform provided by Facebook is governed by the Facebook terms and conditions. Furthermore, the nature of Facebook allows the crowd to easily interact with the crowdsourcer.

\section{Discussion}

The discussion above illustrates the value of the concept "crowdsourcing" in reaching an understanding of the way in which Facebook is used to find missing persons. Certain members and Facebook communities in the network act as the "crowd" (Figure 2) whereas others act as the crowdsourcers (Figure 1) who have a specific task - finding missing people. The crowdsourcing platform is Facebook. Using crowdsourcing as analytical lens also shows the shortfall of using Facebook in the quest to find missing persons. Gao et al [11] believe that social media as crowdsourcing tool lacks inherent coordination capabilities when used for disaster relief. Although the phenomenon of 
missing persons cannot be considered a disaster, there are similarities in the processes needed to react to the disaster and to find missing persons: there is a need to not only share but also coordinate information among different groups and organisations. We have found evidence of close cooperation between the missing persons groups and the police in some of the posts. This means that Facebook is used not only as a way of mobilising crowds (sharing messages) in this context. We therefore believe that if authorities use social media in a more focused and coordinated way, or combine it with existing crowdsourcing tools, the "power of the crowd" can truly be realised in the search for missing persons. Despite the fact that "the crowd" might not literally result in the locating of a missing person (only two posts made reference to the locating of a missing person through the actions of the "the crowd"), the crowd seems to be effective in other ways. It renders emotional support to the crowdsourcer. Technological advances, such as the Internet, have created new opportunities for social interaction and support among community members [13]. The Internet supplements the traditional operations of locating a missing person - through the processes of authorities and at the same time extend emotional support to the crowdsourcers individually and collaboratively.

\section{Conclusion}

This research paper aims to understand how Facebook is used in the quest of locating missing persons. Crowdsourcing is used as analytical lens and explains the interaction between communities indicated in the graphs as those of the crowdsourcer (Figure 1) and those of the crowd (Figure 2). It further illustrates the "powerful propagation capability" [11] of Facebook as crowdsourcing platform. It also points towards the necessity of a more coordinated effort in order to realise the benefit of Facebook as crowdsourcing platform. This might imply an expansion of the traditional search processes by authorities to officially include social media. In addition, it is argued that this network of communities act not only as a massive search party but also as a source of emotional support. This study can be seen as exploratory in the sense that it included data from a short time period. More research is needed to apply current research on crowd-sourcing to such systems to understand and improve its effectiveness. 


\section{References}

1. A child goes missing every five hours in SA - MCSA, 4 June 2015 http://www.news24.com/SouthAfrica/News/A-child-goes-missing-every-five-hours-in-SAMCSA-20150604

2. $4,432,880$ Missing Persons Vanished In Past 20 Years Monday, 26 August 2013, 11:20 In Press Release: International Rewards Centrehttp://www.scoop.co.nz/stories/WO1308/S00441/4432880-missing-persons-vanished-inpast-20-years.htm

3. Missing persons: A handbook for Parliamentarians, Number 17. 2009. http://www.ipu.org/PDF/publications/missing09-e.pdf

4. "South African Social Media Landscape 2014." 2014. http://www.worldwideworx.com/wp-content/uploads/2013/10/Exec-Summary-SocialMedia-2014.pdf

5. Howe, J. 2006. The rise of crowdsourcing. Wired. Issue 14.06 - June 2006. http://www.wired.com/wired/archive/14.06/crowds.html

6. NGO helps find more than 450 missing people, 22 December 2015 http://ewn.co.za/2015/12/22/NGO-helps-find-more-than-450-missing-persons

7. Wayland, S. 2009. Supporting those who are left behind. http://www.missingpersons.gov.au/ /media/mp/files/pdfs/supporting\%20those\%20who \%20are\%20left\%20behind.pdf

8. Johnson, E. C., Kristof-Brown, A. L., Van Vianen, A. E., De Pater, I. E., \& Klein, M. R. (2003). Expatriate social ties: Personality antecedents and consequences for adjustment. International Journal of Selection and Assessment, 11(4), 277-288.

9. Wang, X., \& Nayir, D. (2006). How and when is social networking important? Comparing European expatriate adjustment in China and Turkey. Journal of International Managmeent, 12, 449-472.

10. Hosseini, M.; Phalp, K.; Taylor, J. and Ali, R, "The four pillars of crowdsourcing: A reference model," Research Challenges in Information Science (RCIS), 2014 IEEE Eighth International Conference on, Marrakech, 2014, pp. 1-12. doi: 10.1109/RCIS.2014.6861072

11. Gao, H; Barbier, G and Goolsby, R. 2011. Harnessing the Crowdsourcing Power of Social Media for Disaster Relief. IEEE Intelligent Systems, May/June 2011.

12. Rahwan, I, Dsouza, S., Rutherford, A., Naroditskiy, V., McInerney, J., Venanzi, M., Jennings, N.R. and Cebrian, M. (2013). Global Manhunt Pushes the Limits of Social Mobilization. Computer, 46(6), 68-75.

13. Sarason, I., \& Sarason, B. (2009). Social support: Mapping the construct. Journal of Social and Personal Relationships, 26(1), 113-120. 